\title{
Social determinants of elderhood
}

\author{
The editors speak to Louise Aronson, geriatrician and Pulitzer Prize finalist, about how old age is perceived and \\ defined, and the influence of social determinants on health. Aronson reflects on her experiences caring and \\ advocating for older adults, and outlines some of the challenges to be addressed during the UN Decade of \\ Healthy Aging.
}

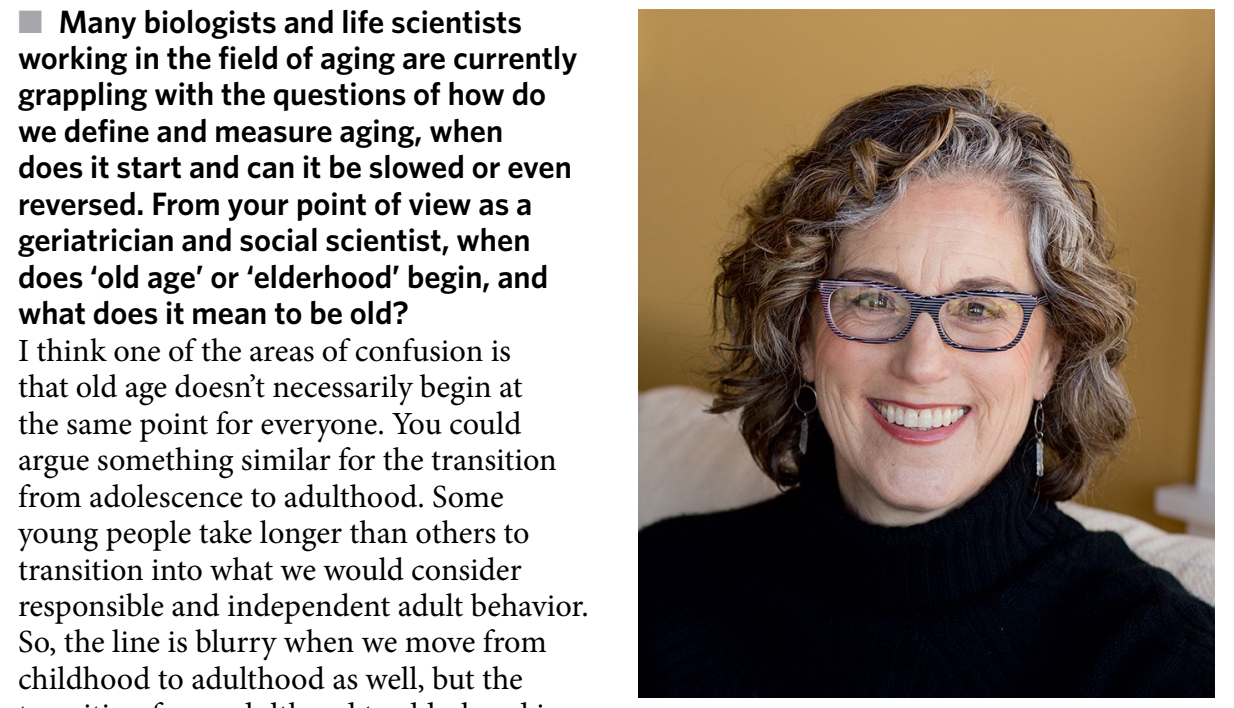

transition from adulthood to elderhood is even more complex. We know aging has not only biological and genetic components but also many components that have to do with your luck, or lack thereof, in regard to socioeconomic status. In the USA, there are differences in lifespan of up to 30 years depending on your ethnic group and which state you were born in. So, for instance, you can be a Native American in the Dakotas and your life expectancy might be into your 50 s or early 60 s, but if you're an immigrant from South Asia in Massachusetts, you could live 30 years longer. We now know that stress makes a big difference and can have an influence across generations, and that access to care continues to be a barrier for many people. I don't think there's a line; it's not like an on/off switch; old age begins insidiously. For childhood and adulthood, there's a clear developmental progression, and almost everybody goes through the same sequence (barring serious disease). With old age, there is also a sequence, but not everybody goes through it necessarily. Sometimes there are jumps where people miss stages. For example, if you think about moving from middle age to what you might call the 'senior years', there's some blurring and overlap. Those are years where people are still quite functional but are liable to start having an array of chronic diseases, such as arthritis, hypothyroidism, high blood pressure, cataracts, hearing loss and
Socio-medically it helps to name a line, but I also think we'll do a better job of dealing with aging generally if we acknowledge its many decades and its diversity in the same way we already do for childhood and adulthood. We don't expect a 55 year old to run as fast as a 25 year old, and we don't expect a 25 year old to be as mature or make as good decisions as a 55 year old. We know there are differences, but we somehow feel like it's okay to lump 68 years old with 88 or 98 years old, which makes no sense to me.

Credit: Photograph courtesy of Anna Kuperberg

so on, regardless of how otherwise healthy they are, because the parts wear out. And it may or may not make any difference in their life. In elderhood, there's not a steady progression and chronological age matters, but functional and health status as well as social fortunes are bigger players.

So, when does old age start? It depends on how you define it. A lot of people would define it as an attitude or behavior, but I think that perspective undermines accurate depictions of the full diversity of elderhood. We know that people who've been really stressed sometimes have many of the features of old age in their 50s, and people who've taken really good care of themselves can appear younger. If you look historically, old age has almost always been placed between the ages of 60 or 70 , and that was even when the average lifespan was much younger. There's an economist at Stanford called John Shoven who mapped out age stages based on your chance of death and showed that over the last hundred years, middle age, old age and elderly status all moved to later in the lifespan. But biologically, for most people it's still somewhere in that range, and everyone is in elderhood by age 70 .
What is the most appropriate terminology for referring to older adults, and is this different in a clinical versus social context? You often use the term 'elder'. Is this a conscious choice, and what is the rationale behind the use of that term? In the medical press, you're required to use 'older adult'. That's the only terminology you're allowed to use, which I actually think is inaccurate and adds to ageism, because older is a relative term. My mother is an older adult compared to me, and I am an older adult compared to our medical students. These relative terms aren't sufficiently helpful. We need absolutes, and we have absolutes for other life stages. At 87, my mother is old. Full stop. The biggest problem with the language of old age is there is so much ageism that nobody likes any of the terminology. Using the word 'adult' is considered good, because it's good to be an adult and it's bad to be an elder or an older person in our societies. 'Older adult' panders to the very ageism it purports to address. I strongly disagree with that approach. I think the way to combat ageism is to make people comfortable with all the terminology, because when you actually look up the definitions of these words, there is no negativity associated with them, no judgment inherent in this language. What it states is simply that you have been around longer than others. It is a chronological fact. When we call someone young, it's also simply a statement of fact, and until people become comfortable saying "I'm old. I'm a senior. I'm elderly", we are never going to have a society or healthcare system that addresses the needs of older people adequately. If the people in 
those groups keep distancing themselves from that category and don't stand up for it, you will never have the political and social will to provide policies and services to older people that are analogous to those we already provide to people in childhood and adulthood.

I use the term 'elder' for a couple of reasons. I initially wanted to call the book I wrote Oldhood and not Elderhood, and I published an article in the New York Times using that term, but someone pointed out to me that this presented a grammatical problem: in childhood, the person is a child, and in adulthood, the person is an adult, but in oldhood, the person is not an old. They can be old, but it's not a noun; whereas in elderhood, the person is an elder. Also, 'old' can be applied to cheese, wine and computers, not just people, whereas an elder is always a human being who has been around longer than most, and there are often more positive connotations associated with community elders, including respect, wisdom and knowledge. So, it has grammatical reasons to be the choice, but it is also more appealing to people generally.

\section{What is healthy aging?}

I think there are multiple components to healthy aging. There's genetic luck, social luck and medical luck, and there are some things we still don't fully understand about diseases yet, like why some people get cancer when others with seemingly similar exposures do not. There are all those components and then there are behaviors, which are facilitated by all these other types of luck. It is clear that if you lead a relatively healthy lifestyle by eating mostly plants and whole grains, exercise regularly, don't smoke, don't do drugs, have alcohol in moderation and get a good night's sleep, all these things can, if not completely, prevent many of the diseases and conditions that we associate with aging, or at least delay them for years to decades, depending on the person. So, I think healthy aging is retaining the functional and health status of an adult longer into elderhood than is usual at this point in time.

\section{"healthy aging is retaining the functional and health status of an adult longer into elderhood than is usual at this point in time."}

Medicine and biology, in general, are leaving out social context, but there's nothing that happens to human beings absent of social context. And this can also be said for conducting research on aging as well, whereby the questions you ask and seek to answer are influenced by who you are in this world, and how they are answered is influenced by certain cultural ideologies of science at this point in history. For example, the initial conception of successful aging by Rowe and Kahn in the late 1990s captured some of what matters, but it didn't take into account that you might not be able to afford or have access to healthy food, be able to exercise safely or all these other things that have since become more apparent to the larger world.

\section{We've now entered the UN Decade of Healthy Aging, which is a global initiative that will hopefully lead to increased col- laborations across sectors and large-scale societal changes. What sort of societal change could help achieve better health and inclusion for older adults?}

I think the World Health Organization's age-friendly liveability framework makes sense as a guide for achieving the goals of the Decade of Healthy Ageing (Global Age-friendly Cities: A Guide; World Health Organization, 2007). Look at things like parks, for instance. You've got the kids' playground and then you've got basketball courts and running tracks, but not necessarily the sorts of things we want as we get older. You want places where people can safely walk, play pickleball, do Tai Chi and all those things that prevent falls and are low impact but beneficial. There's also a huge overlap between elderhood and adulthood in terms of the types of exercises people do, particularly as people get into middle age. When you look at a park, you should be able to see spaces designed for itty-bitty kids all the way up to frail elders; you should be able to see all segments of society.

\section{"When you look at a park, you should be able to see spaces designed for itty-bitty kids all the way up to frail elders; you should be able to see all segments of society."}

But it's not just about communal spaces: there are other sectors of society that need to become more age-friendly and inclusive in order to shift attitudes about aging and contribute to better health. Clothing and fashion is a good example. You've got clothing for all different ages, but as people get past 75 or 80 years old, their body really changes. We get shorter, the foot arches flatten, you get less fluid in the intervertebral discs, and you have more tightening of the ligaments, making your ribs closer to your hips and your stomach can stick out, even if you're thin. All of this means that your pants and clothes have to be different. You could still make a person look great if you wanted to by designing clothes for older people with these changes in mind. But making clothes for old people is considered not fashionable. Or people will also say that demand is low, that old people don't care about what they wear or how they look. They do care. It's because they go shopping and most of what fits, or is comfortable, is ugly. If you could dress in a way that made you feel good about yourself, you'd have more agency to stand up for yourself. You'd go out and do more things. That would add to healthy aging.

Technology is another good example. The pandemic has meant that a lot of people who thought they had missed the boat of using digital devices and new technology are now learning to do so. There are many community-based organizations that have helped people get devices and set them up so they can use Zoom and follow exercise programs or participate in social gatherings. So, I think that is opening up opportunities. But there are so many more opportunities with technologies than people are taking advantage of. For example, low-cost mental health interventions via video in older adults are showing that providing people with the technology and teaching them to use it improves their lives. Another advantage is that it takes a lot of the fuss out of attending a health appointment. Particularly for someone who is not feeling well or having trouble motivating themselves - if you don't have to get dressed up, leave your house, figure out where to go and how to get there, you are more likely to show up. And virtually, the clinician can see a bit about their social and physical context, if the old person lets them. As a clinician who did house calls for many years, seeing what's really going on in the physical and social environments of people's lives is incredibly helpful to understand how to help them.

How do you see the different disci-
plines of aging research working together
to achieve common goals; for instance,
biologists in laboratories and clinicians in
different specialties?
Sadly, there's a lot of tribalism. There is a lot
of sweet talk about collaboration, but mostly
everybody's in their silo with their different
jargons and their different priorities. And
with fewer dollars to go around, there's more
competition. At my institution, University of
California San Francisco (UCSF), we have
an outpatient practice that does not keep a
wait list because so many people would be
on it, and yet we won't hire more clinicians.
A few years ago, UCSF built a huge new


pediatric hospital. We're building a new adult hospital. No mention of old people. Wealthy donors want to give money to what they call 'anti-aging' because they want to 'stay young and live forever', but they don't want to give money to the care of the people who are old now. Then once they or their parents reach a certain age and get sick, we're called to do an emergency visit; we, in geriatrics - because eventually almost everyone needs us. So, there is this complete disconnect, and I think we need to say, "why aren't we doing more to give much better care for old people?". We know how to do this and we could do so much more of it to help people right now, health systems just don't prioritize it the way they prioritize research.

What has your experience been during the pandemic as a clinician working with older adults, and how has the pandemic impacted on their lives?

The pandemic has harmed different groups in different ways. In my clinical experience working with older adults, I have seen some real-life examples of what the literature shows, which is that the people who started out with some social isolation, depression or anxiety are having a harder time than those who did not have those conditions to begin with, including people who have more resources: personal, social, digital and otherwise. In the USA, we've also seen health inequities, so that far more disease has impacted people who are poor, and, because of the way we run our country, people of color, also. We know old people have died hugely disproportionately globally, but at the same time, we also know kids are really in trouble having missed school and having trouble concentrating, and there are people who have recovered but are changed forever by having been so sick. So, I want to be clear that I understand there are many ways to suffer, but if you look at the Centers for Disease Control website, you have all this information for lay people or providers. On health information websites, there is usually a special section for kids and teens, but on most such sites, there is no place for elders. There's nothing specific about older adults unless it's found under 'special populations' or under long-term care facilities, which have been hotbeds of disease, but that's less than $2-3 \%$ of older adults, so what about the other $97-98 \%$ during a pandemic where $80 \%$ of deaths are in elders? So, we need to think about how we transform public health that includes elders. This is absolutely critical. Our public health structures are underfunded and most of the people who've been dealing with older adults have no background in it, whereas the people who are dealing with public health for adults and kids are specifically trained to do so. So, that's a structural health inequity.

You've had many successes and an impressive career to date. What would you say is one of your proudest achievements and biggest setbacks?

I'd say my book (Elderhood: Redefining Aging, Transforming Medicine, Reimagining Life) is one of my proudest achievements with the greatest impact. It's beyond anything I could have imagined. I'm constantly being quoted or mentioned, or I'll agree to do speaking engagements and they'll say, "we had to switch platforms because so many people signed up". That would have never happened before. Being the Pulitzer Prize finalist was pretty cool, also. I was in virtual clinic when I found out. My phone started going off and I thought maybe there was a war or something!

In regards to biggest setbacks, I experienced career burnout a few years ago and I gave up my then practice and stopped my job. It was horrible at the time obviously, but it probably ended up being good for me. I really reconsidered my life, and it enabled me to do everything I've done in the last five years. So, it was a setback, but it's hard for me to see it now in the negative light in which I lived it at that time.

An earlier setback was when I first started as a geriatrician. The way the program was set up was classic university-focused, prioritizing research, the potential outcomes of which would benefit older people in the future, over providing high-quality care for people who were old at the time. For me, this is a moral imperative: I'm not willing to sacrifice the old people of today for the old people of the future. So, I felt I had to leave, and that felt like a bit of a setback in my career. Yet, from working in different healthcare settings, I learned what it was like to practice at a place where the patients were put first unlike in an academic setting, but I also learned that I like an academic setting because I value the intellectual engagement and being pushed by all these smart people asking smart questions.

\section{"For me, this is a moral imperative: I'm not willing to sacrifice the old people of today for the old people of the future."}

What originally motivated you to
choose your path, and do you have any
advice for early-career female researchers
or geriatricians that you would want to
pass on based on your experience?

I went into medicine because I wasn't convinced that the other things I was thinking of doing (anthropologist, or literature or history professor) would be the sort of contribution I wanted to make. When I started, I thought I would work with refugees. Then, when I finished medical school in 1992, it was early in the AIDS era, so I thought I might work with AIDS patients. But what I saw across my residency was that there was one group that nobody was working with and that one could seriously harm by applying the rules of adult medicine that I was being taught, which was old people. And because I am a person who likes history, literature and anthropology, I thought working with old people would give me an opportunity to work with individuals who had lived a long time and who are from all over the world so I'd have to be a bit of a historian and anthropologist to provide them with good medical care. I think the breadth and diversity of older lives and opportunities and challenges of geriatric care has kept me passionate. What also motivated me was making a difference, and the thing about old age is that it's been so undervalued and understudied that we can make a big difference in so many ways.

As for my advice to women, follow what interests you, even though you might get some pushback. We've learned the huge potential for women to be able to make a difference we didn't actually have women's health until women went into medicine. Ask the questions that interest you. What we're learning certainly in the USA is that as we include more people of color, we're asking different questions, and that's leading to better care and better representation. So, who you are can, should and will inform what questions you ask. And you should pursue those. Just because they haven't been asked before, doesn't mean they're not worthy, and it may be because someone in your environment doesn't understand why they're important. Also, work on your communication skills, because one of the things we know across sectors, not just in medicine or research, is that women tend to underplay their achievements and unnecessarily apologize for things. Be confident in who you are and the value of what you think and do, and present yourself that way. It's about recognizing that being there makes a difference in part because of the different questions you ask are because of who you are. That's the only way we can create a healthcare system and a biological knowledge base that speaks to everybody's needs in society.

\section{Interviewed by Briony Jain}

Published online: 14 May 2021

https://doi.org/10.1038/s43587-021-00066-y 